\title{
A Few Potential Treatments of Asthma in Vietnam
}

\author{
Huynh Tan Hoi
}

\section{Huynh Tan Hoi}

Language Department, FPT University, VIETNAM.

\section{Correspondence}

Huynh Tan Hoi

Language Department, FPT University, VIETNAM

E-mail: hoiht@fe.edu.vn

History

- Submission Date: 23-12-2020;

- Review completed: 21-02-2021.

- Accepted Date: 01-03-2021.

DOI : 10.5530/pj.2021.13.81

\section{Article Available online}

http://www.phcogj.com/v13/i3

\section{Copyright}

(C) 2021 Phcogj.Com. This is an openaccess article distributed under the terms of the Creative Commons Attribution 4.0 International license.

\begin{abstract}
Asthma is a chronic condition that can be fatal if it isn't treated promptly during an attack. Patients with an asthma attack cannot breathe enough air to supply the body with oxygen and within minutes, the patient can die. In Vietnam today, people can buy antibiotics on their own without the need of a doctor to prescribe or visit. Many people who only see signs of coughing, wheezing have voluntarily bought antibiotics for use. The overuse of antibiotics is very common in asthma patients. In fact, antibiotics are not effective in most types of asthma. Abuse of antibiotics is not only ineffective, but also makes the patient more tired, reduces resistance, and digestive disorders. Some antibiotics can even lead to acute asthma attacks. This article covers some of the remedies that can eradicate asthma with a combination of severa fairly safe treatments. Through analysis of the scientific composition and current studies, it is possible to treat asthma and maintain good health.

Key words: Asthma, Medicine, Patient, Prevention, Health.
\end{abstract}

\section{INTRODUCTION}

Asthma is a disease of the respiratory tract. It is characterized by episodes of dyspnea that start suddenly when there is a trigger. Factors that trigger asthma attacks vary from person to person, usually allergens such as odor, animal hair, insects, physical activity, etc. We cannot completely treat it. In this disease, the current therapies are just to control the disease with two main goals of reducing the number of recurrences and preventing severe cases. ${ }^{1}$ Patients with long-term asthma often know about imminent symptoms such as coughing, sneezing, fatigue, etc. and they can completely prevent the disease from progressing when promptly using fast acting drugs. Patients can completely live and function as normal people if the disease is monitored and treated properly. ${ }^{2}$

\section{CONTENT OF RESEARCH}

\section{Definition of asthma}

To understand asthma, we first need to visualize how the airways work. The air passages are tubular shaped to help carry air in and out of our lungs. People with asthma experience inflammation in the airways. ${ }^{2}$ Inflammation causes the airways to swell, become very sensitive, and tend to react strongly to certain inhalers. When the airways are irritated, the surrounding respiratory muscles tighten. ${ }^{3}$ This narrows the airways, preventing air from entering the lungs. The edema can also get worse, causing the airways to narrow even more. The cells in the respiratory tract can make more mucus than normal. Mucus is a thick, sticky substance that can narrow your airways. ${ }^{1}$

Asthma is a chronic respiratory disease that currently has no cure for Western medicine. Asthma patients must regularly use bronchodilators to temporarily stop their attacks. ${ }^{4}$

\section{Symptoms of asthma}

Common signs and symptoms include more coughing spells at night or early in the morning, making it difficult for patients to sleep. The patient breathes or makes small sounds when breathing. The patient may feel chest pressure, which may be described as something pressing on the chest. ${ }^{5}$

Next is the symptom of difficulty breathing. People with asthma can't breathe well or feel out of breath They feel unable to push the air out of their lungs (Figure 1).

\section{Reasons}

Currently, we do not know the exact cause of this disease. The researchers suggest that interactions between certain genetic and environmental factors trigger asthma, most often in the early stages of life. These factors include:

- The allergy is inherited;

- Parents with asthma;

- Having a number of respiratory infections during childhood;

- Inhalation of certain allergens in the air or exposure to infectious diseases in childhood or early life when the immune system is developing.

Therefore, exposure to stimulants such as cigarette smoke can cause the patient's airways to react more aggressively than substances in the air. ${ }^{6}$ The activators that patients experience may be different from those with other asthma. Stimulants can be as the following:

- Allergens caused by dust, animal hair, mold, plant pollen, grass and flowers;

- Irritants such as cigarette smoke, air pollution, chemicals or workplace dust, compounds in home décor products and sprays (such as hair sprays); 


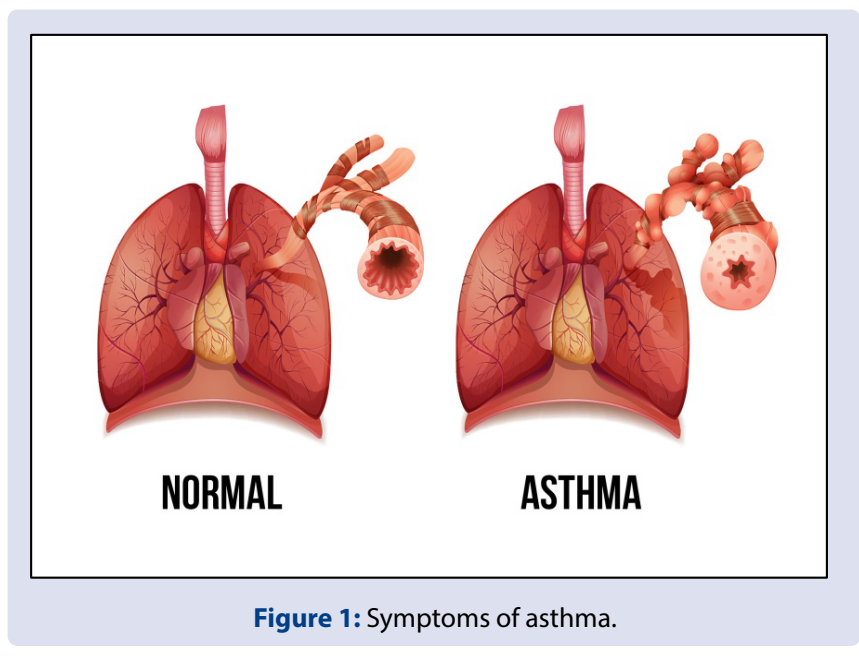

- Medicines like nonsteroidal anti-inflammatory drugs;

- Sulfite in food and drinking water;

- Upper respiratory tract infections such as colds;

- Physical activity, including exercise.

\section{People at risk of asthma}

According to WHO, asthma is a common medical condition in children. In fact, asthma affects people of all ages but it often starts when we are young. Among children with asthma, the rates of boys are often higher than girls. ${ }^{7}$ But in adults there is an inversion, more women with asthma than men. Currently, there is no clear evidence of how sex and sex hormones play a role in causing asthma. Some people who exposed to certain irritant chemicals or industrial dust in the workplace are at increased risk of asthma. ${ }^{4}$

\section{Some methods being used to treat asthma}

The doctor might make a diagnosis of asthma based on many factors. The first is the family history; the doctor will ask if the patient's family has any history of asthma and allergies. ${ }^{8}$ The doctor may also ask if the patient has asthma symptoms and when and how often they occur. Besides, the doctor can do a physical exam by listening to their breathing and looking for signs of asthma or allergy. In addition, the doctor will check lung function using a test to check how a patient's lungs are working. ${ }^{6}$ Asthma is treated with two effective and long-term drugs that help reduce inflammation in the airways and prevent symptoms from the start. These drugs include corticosteroids, cromolyn, omalizumab (anti-IgE). If the patient has severe asthma, they may need to take corticosteroid pills or tablets for a short period of time to manage the condition. For quick-acting medications, all people with asthma need quick-acting medication to help minimize possible flare-up symptoms. ${ }^{9}$ The rapid acting beta2 group (Albuterol, pirbuterol, levalbuterol or bitolterol) is the first choice. Other medications include ipratropium (anticholinergic agents), prednisone and prednisolone (oral steroids). Patients should also take rapid-acting medications when they first start having asthma symptoms.

\section{Some living habits help patients limit the progression of asthma}

If they have asthma, patients will need long-term care. Successful asthma treatment requires proactively taking care of your own health and sticking to your treatment plan. ${ }^{4}$ This plan will help us know when and how to take your medications, and help patients identify asthma triggers and manage their condition if their symptoms get worse. To control asthma, patients should work with their doctor to manage their asthma. Children should receive health education and take the initiative to take care of their medical condition. It is important that the patient takes an active role in the management of bronchial asthma by actions such as. Patients should be sure to maintain physical activity. Physical activity is an important part of a healthy lifestyle. ${ }^{8}$ Patients should get a flu shot every year, especially children. Patients should be aware of their asthma symptoms because this is also a way to help them monitor the progress of their disease, helping them to be under good control. With the advent of new drugs, asthma treatment strategies and guidelines are updated every year to improve asthma control. ${ }^{9}$ With new research and advancements in medicine, a patient's asthma has a better chance of stable control. In addition to the role of the doctor and medication, the patient's own role in controlling the disease is also very important. Patients should avoid irritants, stop smoking as smoking can lead to chronic irreversible respiratory infections, exercise, and regular use of medication as prescribed by the doctor. ${ }^{10}$ Patients need to actively record symptoms and the number of times to take medications in a week or a month to provide information to the doctor about the stability of the disease. If the disease recurs several times a week or a month, the patient needs to be on a ladder of treatment. Some asthma cases patients suffered from their childhood go away on their own in adulthood. Parents do not worry too much, but take time to learn more about how to prevent and manage diseases for children. ${ }^{3}$

\section{Using perilla macrostachya to treat asthma macrostachya}

Perilla is used in Chinese medicine with many medicinal uses. Perilla macrostachya extract has antioxidant, anti-inflammatory, anti-allergic, anti-depressant, anorexia and prevents tumors from appearing and growing. ${ }^{11}$ According to folk medicine, perilla macrostachya has a spicy taste, many essential oils have antibacterial properties, is high in fiber and does not cause heat despite the moisture (Figure 2).

According to research, perilla macrostachya is good for use as an herb for good asthma treatment in all three types of heat, wind, and phlegm. In addition, perilla macrostachya is also used to treat many ailments such as colds, fever, sweating. ${ }^{10}$ We can use perilla macrostachya to cure asthma in children quite effectively. We can combine perilla macrostachya, male papaya flowers, and star fruit flowers. Then, we put them in a cup; add a little sugar and a little water to boil the mixture for 15 minutes. The patients can drink it slowly to let the medicine seep into their tongue. We also remember that it is used for children who have some symptoms such as sweating a lot or having fever. ${ }^{12}$

\section{Traditional medicine for asthma treatment}

For a long time, Oriental medicine has become a cure that many patients as well as medical experts appreciate. Oriental medicine has benign advantages, uses natural herbs, and is safe and effective. ${ }^{13}$

\section{Ginger remedy for asthma}

Ginger is popularly grown in many regions of Vietnam. Ginger is a medicine as well as a spice in daily meals. Not only that, this is also

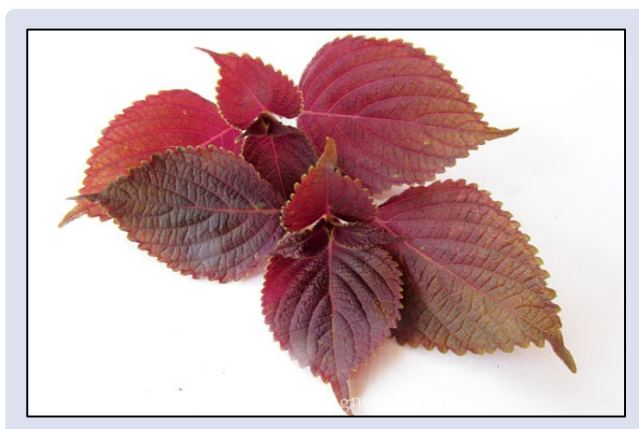

Figure 2: The image of perilla macrostachya. 
a popular ingredient in life with great uses such as treating colds, coughs, vomiting, and headaches. Even more surprisingly, ginger is also a medicinal remedy for asthma since it has some great scientific composition inside (Figure 3)

Patients can take ginger powder 3 times a day, about 50g each time regularly and continuously for 3 months, will help improve symptoms of asthma. In addition, patients can prepare ginger by other ways such as cutting ginger into small pieces, boil with boiling water and drink before bedtime every day. Ginger tea is incredibly easy to drink and has health benefits.

\section{Using gallbladder of varanus salvator macromaculatus}

Varanus salvator macromaculatus is known in many regions of Southeast Asia. Its gallbladder has a good effect on asthma and high blood pressure, etc. According to modern medical research, its gallbladder contains active ingredients that can aid digestion, stimulate fat absorption and vitamins, helps regulate the balance of cholesterol, glucose, and triglycerides (Figure 4). It also has steroids that are antiinflammatory and analgesic. This gallbladder can be used 2 times in the morning and at night, depending on the age.

Treating asthma with folk remedies is safe and is with low cost. ${ }^{14}$ However, this remedy only works to relieve the symptoms of asthma in the mild stage but does not cure the root. In particular, many folk tips are difficult to implement and have not been scientifically proven. If done incorrectly, it can cause serious health consequences. For oriental medicine, these are remedies that have been researched, prepared and clinically proven by traditional medicine, having very good effects on patients, especially difficult to cure like asthma.

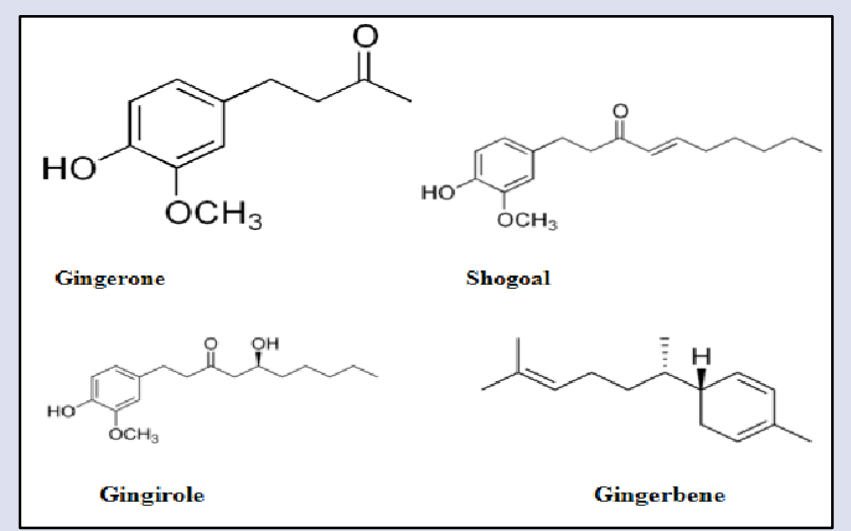

Figure 3: Scientific composition of ginger.

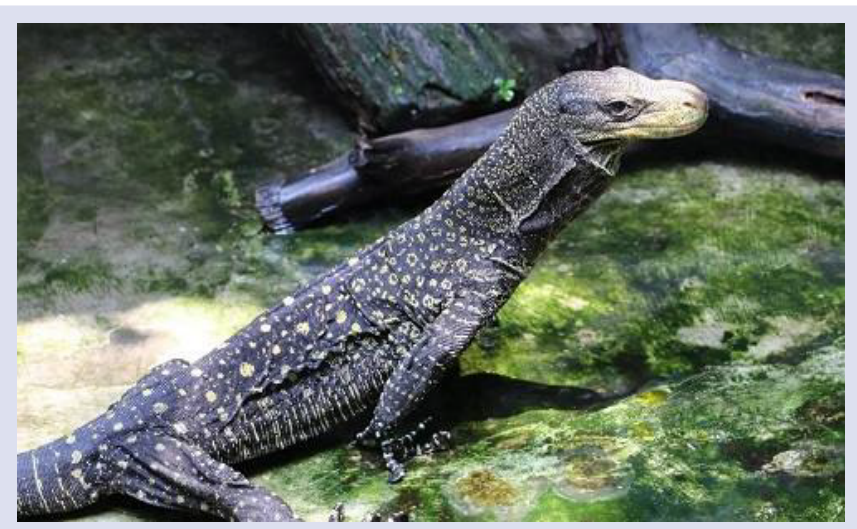

Figure 4: The image of varanus salvator macromaculatus.

\section{CONCLUSION}

To cure asthma, in addition to adhering to treatment regimens, we should combine with diet and activities to control and minimize asthma attacks. At the same time, we should monitor and periodically evaluate disease status. Currently, the main method of asthma treatment is to use Western medicines to control asthma symptoms. These drugs containing corticosteroids are potentially many unwanted side effects. Overuse of high doses causes drug dependence, making asthma worse. More dangerous thing is causing liver failure, kidney failure, cardiovascular effects, etc. Folk remedies for treating asthma at home are have great effectiveness long ago and need to take into consideration.

\section{ACKNOWLEDGMENTS}

I would like to send my warm thanks to those who gave me great advice to complete the paper.

\section{CONFLICTS OF INTEREST}

There is no conflicts of interest in the paper.

\section{ETHICAL CLEARANCE}

I am ensuring the quality and integrity of my research. The ideas and opinions expressed in this paper are my effort.

\section{REFERENCES}

1. Lazarus, S. C. Emergency treatment of asthma. New England Journal of Medicine. 2010; 363:755-64.

2. Bacharier, L. B., Boner, A., Carlsen, K. H., Eigenmann, P. A., Frischer, T., Götz, M., ... \& Platts - Mills, T. Diagnosis and treatment of asthma in childhood: a PRACTALL consensus report. Allergy. 2008;63:5-34.

3. Drazen, J. M., Israel, E., \& O'Byrne, P. M. Treatment of asthma with drugs modifying the leukotriene pathway. New England Journal of Medicine. 1999;340:197-206.

4. Hoi, H. T. Some Kinds of Medicinal Herbs for the Treatment of Sinusitis. Biomedical and Pharmacology Journal. 2020;13:92732.

5. Dowlath, M. J. H., Karuppannan, S. K., GI, D. R., SB, M. K., Subramanian, S., \& Arunachalam, K. D. Effect of Solvents on Phytochemical Composition and Antioxidant Activity of Cardiospermum halicacabum (L.) Extracts. Pharmacognosy Journal. 2020;12.

6. Hoi, H. T. Great Effect of Fallopia Multiflora and Other Herbs in Poliosis Treatment. Pharmacognosy Journal. 2020;12.

7. Papi, A., Caramori, G., Adcock, I. M., \& Barnes, P. J. Rescue treatment in asthma: more than as-needed bronchodilation. Chest. 2009;135:1628-33.

8. Quang, M. N., Tan, H. H., \& Hoang, C. V. Some Effective Ways for Treating Flu. In Proceedings of the 2019 2nd International Conference on Electronics and Electrical Engineering Technology. 2019:123-6.

9. Dash, G., Mohanty, K. K. G. R., Sahoo, D., Mahalik, G., \& Parida, S. Traditional medicinal plants used for the treatment of asthma in Bhubaneswar, Odisha. Int J Herb Med. 2018; 6:57-60.

10. Hoi, H. T. Affordable and Effective Folk Remedies To Treat High Blood Pressure And Other Diseases In Tropical Countries. International Journal of Pharmaceutical Research. 2020;12.

11. Huntley, A., \& Ernst, E. Herbal medicines for asthma: a systematic review. Thorax. 2000; 55:925-9. 
12. Tiwari, S., \& Talreja, S. Importance of Cinnamomum Tamala in the Treatment of Various Diseases. Pharmacognosy Journal. 2020;12

13. Nguyen, D. T. T. Combining a Number of Medicinal Herbs in order to Treat Fatty Liver Disease. International Journal of Pharmaceutical Research.2020;1.
14. Sumantri, I. B., Wahyuni, H. S., \& Mustanti, L. F. Total Phenolic, Total Flavonoid and Phytochemical Screening by FTIR Spectroscopic of Standardized Extract of Mikania micrantha Leaf. Pharmacognosy Journal. 2020;12.

\section{GRAPHICAL ABSTRACT}
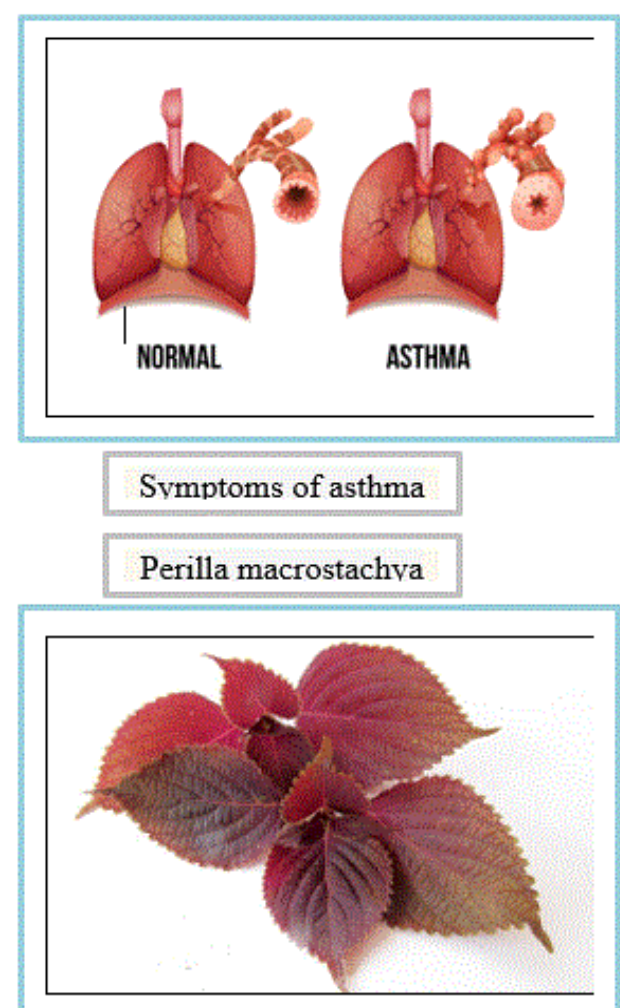

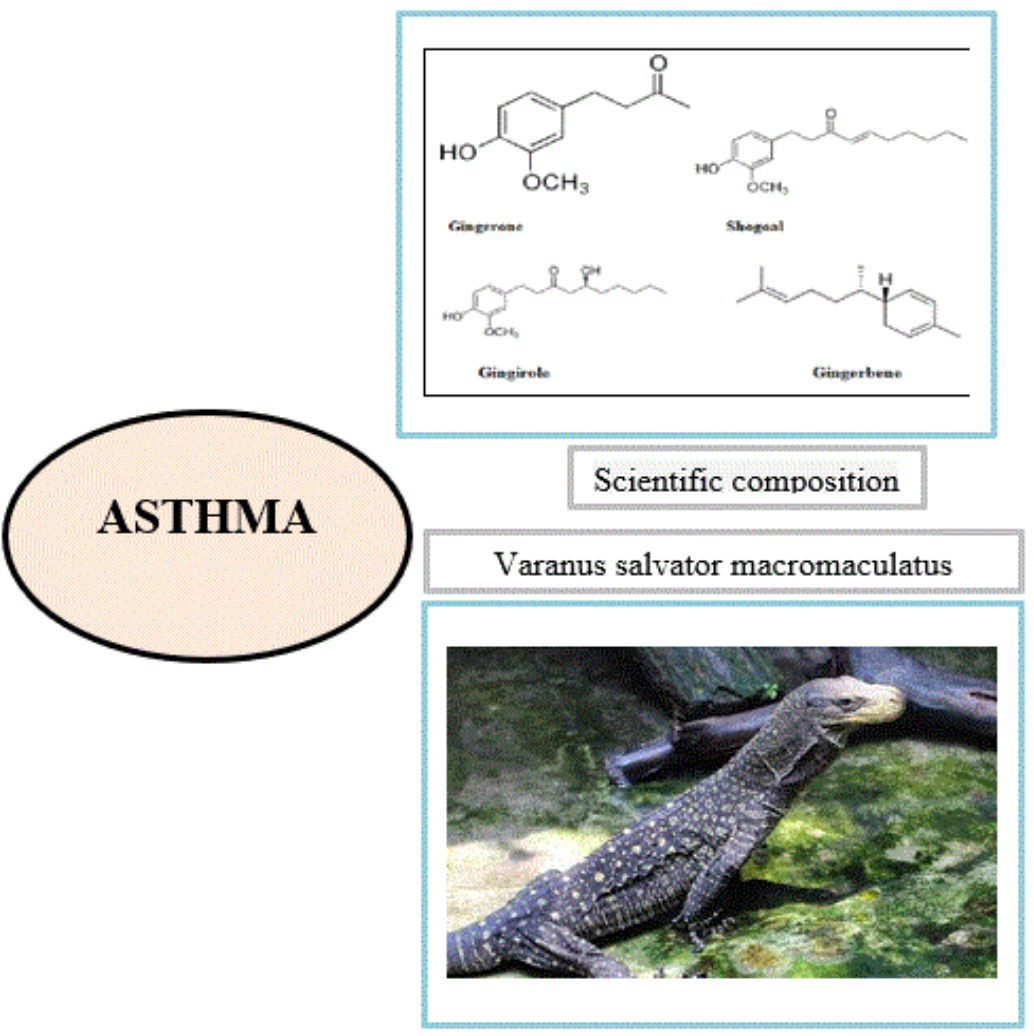

\section{ABOUT AUTHOR}

The author is now a Japanese lecturer of FPT University, Vietnam. His majors are literature, language, medication, environment and tourism. He is now a Ph.D candidate. He speaks English, Japanese and Chinese.

His some recent publications:

1) Hoi, H. T. (2020, July). Impacts of Urbanization on the Environment of Ho Chi Minh City. In IOP Conference Series: Earth and Environmental Science (Vol. 505, No. 1, p. 012035). IOP Publishing.

2) Hoi, H. T. (2019, October). Chickenpox and Quick Treatment, No Scars Left. In Proceedings of the 2019 8th International Conference on Bioinformatics and Biomedical Science (pp. 110-115).

Cite this article: Hoi HT. A Few Potential Treatments of Asthma in Vietnam. Pharmacog J. 2021;13(3): 640-3. 